\title{
A VISÃO DAS CRIANÇAS SOBRE O LAZER ${ }^{1}$
}

Recebido em: 12/05/2012

Aceito em: 25/11/2012

Michelle Araújo Rocha

Luciana Karine de Souza

Universidade Federal de Minas Gerais - UFMG

Belo Horizonte - MG - Brasil

RESUMO: Este estudo buscou conhecer o conceito de lazer de crianças, suas práticas de lazer, a companhia nessas práticas, se se aprende algo com o lazer, quais atividades fariam mais e quais deixariam de fazer. Foram entrevistadas individualmente 41 crianças de 9 a 10 anos de idade, estudantes de escolas públicas ou privadas da cidade de Belo Horizonte. As respostas transcritas passaram por análise de conteúdo, gerando categorias de unidades temáticas semelhantes. O lazer para estas crianças envolve realizar atividades generalizadas com os pais e se divertir. Olhar televisão, descansar, fazer atividades físicas e brincar são as atividades que as crianças realizam em suas vidas como lazer, principalmente na companhia dos pais, amigos e irmãos. $\mathrm{Na}$ visão dessas crianças, o lazer ensina novidades de toda natureza. Gostariam de realizar mais atividades físicas e esportivas, e pouco se manifestaram quanto a atividades de lazer que deixariam de realizar. Há muito a se estudar com relação ao lazer em crianças. Trata-se de uma dimensão importante do bem-estar subjetivo e da satisfação de vida infantil. A psicologia positiva precisa atentar mais para o campo de estudos do lazer, e este último pode se enriquecer com a perspectiva subjetiva do estudo do bem-estar e da felicidade, especialmente com o foco na visão da criança sobre o descanso, o prazer e oportunidades de desenvolvimento e aprendizagem.

PALAVRAS CHAVE: Criança. Atividades de Lazer. Jogos e brinquedos.

\section{CHILDREN'S VIEW ON LEISURE}

ABSTRACT: This study aimed at knowing the concept of leisure in children, their leisure practices, their company during these activities, whether they learn something from leisure, which activities they prefer to do more and which they would like to cease. Forty-one 9 to 10 years old children were individually interviewed, all enrolled in public or private schools in Belo Horizonte, Brazil. Transcribed answers went through content analysis in order to generate categories with similar thematic units. For these

1 Este trabalho relata o terceiro e último conjunto de dados inéditos da dissertação de mestrado da primeira autora, sob orientação da segunda autora, no Programa de Pós-Graduação Interdisciplinar em Estudos do Lazer da Universidade Federal de Minas Gerais. Apoio: FAPEMIG, Fundep/Santander, PPGLazer da UFMG. Agradecimentos: E. Lourenço, A. C. G. Dias, L. C. Martins, T. L. de Carvalho e D. C. Silveira; escolas, pais e participantes. 
children, leisure involves having fun and doing all sort of activities with their parents. Watching television, resting, practicing physical activities and playing are what compose leisure for these children, mainly with parents, friends, and siblings. Leisure also teaches all sort of novelties, according to the participants' view. They also would like to have more physical activities and sports as leisure, and little were said about what they would prefer to abandon. There is still much to be studied on leisure during childhood. It is an important dimension of subjective well-being and life satisfaction in children. Positive psychology needs to direct interest to the field of leisure studies, and this, in turn, could be enriched by the subjective perspective of studying well-being and happiness, especially focusing on how children understand rest, pleasure, and positive development and learning opportunities.

KEYWORDS: Child. Leisure Activities. Play and Playthings.

\section{INTRODUÇÃO}

Recentemente foi proposto um diálogo possível entre os estudos interdisciplinares do lazer e o movimento da psicologia positiva (ROCHA; SOUZA, 2011). O presente trabalho parte da mesma premissa, a qual localiza na interação destas duas áreas a discussão dos benefícios do lazer à criança em termos de qualidade de vida infantil.

Desta feita, a pesquisa aqui relatada, ao contrário da maioria das pesquisas sobre recreação e lazer em crianças na psicologia, não se dedica às crianças em situação de vulnerabilidade social ou com problemas de saúde. Trata-se de uma pesquisa com crianças que não apresentam estas questões como impedimentos ao desenvolvimento e à aprendizagem. O trabalho, portanto, segue a diretriz da psicologia positiva em focalizar os aspectos positivos da experiência humana.

O movimento da psicologia positiva iniciou em 1998 através de Martin Seligman, um psicólogo que assumiu a presidência da sociedade norte-americana de psicologia na época. Segundo ele, a psicologia tradicionalmente se dedica a tratar de doenças, de problemas e de procurar amenizar o sofrimento e as dificuldades em distintos contextos da vida humana. A psicologia positiva congrega esforços para a 
investigação de aspectos positivos da experiência humana, responsáveis por não somente aliviar o sofrimento, mas por tornar as pessoas felizes e com boa qualidade de vida. Assim, aos adeptos da psicologia positiva, interessam estudar questões como virtudes (por exemplo, sabedoria, justiça, coragem, amor), forças (curiosidade, generosidade, gratidão) (SELIGMAN, 2004), bem-estar, emoções positivas e gratificações. Esses aspectos podem ser analisados em três níveis distintos: subjetivo, social e institucional.

Rocha e Souza (2011) entendem que o lazer, enquanto tempo, espaço, cultura, descanso, divertimento e desenvolvimento pessoal e social, e tomado nas suas esferas subjetiva, social e institucional, é um fenômeno capaz, portanto, de proporcionar experiências de felicidade às pessoas. Aqui estão implícitas as premissas dos estudos do lazer de autores como Dumazedier (1979) e Marcellino (1996). Moura (2012) e Dias (2012) notaram, por exemplo, como as práticas de lazer em idosos de distintas condições socioeconômicas são capazes de promover atitudes de generosidade, curiosidade, religiosidade, otimismo e esperança. Em crianças. Rocha e Souza (2012a; 2012b) demonstram como o lazer é facilitador de bem-estar, desenvolvimento saudável e de aprendizagem a crianças também de níveis socioeconômicos diferentes. Rocha e Souza (2011) argumentam, ainda, a estreita ligação entre lazer e amizade nas crianças, posto que o lazer facilita relações de pares saudáveis, e a amizade oferece oportunidades frutíferas de práticas de lazer.

Giacomoni, Souza e Hutz (2012a; 2012b) relatam uma ampla pesquisa sobre bem-estar subjetivo e satisfação de vida em 200 crianças de 5 a 12 anos da cidade de Porto Alegre (RS). As crianças foram convidadas a definir felicidade, e dos temas que mais emergiram das respostas, o lazer foi citado por $87 \%$ das crianças, mediante 
conteúdos como atividades físicas e divertidas, brincadeiras, brincar e brinquedos. Os meninos foram os que mais citaram lazer em suas respostas, bem como as crianças de 5 a 8 anos. Sobre a experiência de ser feliz, as crianças da escola privada mencionaram mais o lazer do que as de escola pública, assim como as crianças de 5 a 6 anos de idade. Esta pesquisa de Giacomoni, Souza e Hutz (2012a; 2012b) demonstrou que, nos esforços para construir instrumentos para avaliar o bem-estar subjetivo e a satisfação de vida em crianças, é necessário inserir a dimensão do lazer como fator componente da felicidade infantil. O trabalho original de Huebner e Gilman (2002), por exemplo, sobre a satisfação de vida infantil considerou cinco domínios específicos nessa abordagem: família, amizade, escola, ambiente e self. O lazer, ou algum de seus componentes, não foi considerado nesse modelo de avaliação.

O trabalho de Lourenço e Jinzenji (2000) é relevante nessa discussão de como crianças mineiras vivenciam o lazer. As autoras compararam os ideais de 307 meninos e meninas de 9 a 15 anos de escolas públicas e privadas de Belo Horizonte, com resultados de pesquisas realizadas com crianças mineiras nos anos de 1929, 1934, 1939 e 1944. Nesse trabalho, foi argumentado que as mudanças observadas nos ideais das crianças, por exemplo, de escolha profissional, teve marcada influência da mídia na sociedade à medida que sua inserção nas famílias era maior.

Outros dados da mesma pesquisa foram discutidos pelas autoras em Lourenço e Jinzenji (1999). Interessantemente, de 1929 a 1998, a aula de educação física passou do oitavo lugar de preferência das crianças para o quarto lugar na visão dos meninos e segundo para as meninas. Contudo, atualmente, há uma queixa saliente sobre as aulas de educação física nas escolas, bem como índices mais expressivos de obesidade e de ociosidade nas crianças brasileiras. Outro dado que chama a atenção é o de trabalho 
preferido em casa. Nos quatro anos estudados, o trabalho doméstico foi o mais apontado pelas crianças como preferido, seguido de "estudar" e de "brincar/esporte". O grande interesse dos meninos por bola e futebol foi gradativamente diminuindo à medida que os jogos eletrônicos passaram ao alcance das crianças a partir da década de 1980, e bastante popularizados na década de 1990. A diferença de gênero para este tipo de jogo, a propósito, é bem pequena na coleta de dados de 1998.

O objetivo do presente texto é apresentar resultados inéditos de pesquisa realizada sobre tempo livre da escola e lazer em crianças de escolas públicas e privadas de Belo Horizonte. Mais especificamente, buscou-se conhecer o conceito de lazer da criança, suas práticas de lazer, suas companhias nessas práticas, se ela aprende algo com o lazer, quais atividades faria mais e quais deixaria de fazer. Dessa forma, almejou-se dar voz às próprias crianças com respeito a suas vivências no tempo liberado da escola.

\section{PASSOS METODOLÓGICOS}

A coleta de dados desta pesquisa foi realizada mediante entrevista semiestruturada individual, gravada em áudio e transcrita para análise, com 41 crianças de 9 a 10 anos de idade, metade meninos e metade meninas, e o mesmo tanto em escola pública e escola privada, da cidade de Belo Horizonte. As escolas foram selecionadas por critério de conveniência, embora se estipulou que ambas se localizassem no mesmo bairro da cidade. Isto ocorreu em virtude de se garantir que as crianças, caso morem nas cercanias da escola, possuíssem à disposição equipamentos de lazer semelhantes, como parques, praças, etc. As crianças participaram da pesquisa somente por vontade própria e após consentimento assinado por pai/mãe ou responsável. O comitê de ética em pesquisa aprovou o estudo que abarca os dados inéditos apresentados na presente 
oportunidade.

As entrevistas ocorreram na escola, em local apropriado. As transcrições foram submetidas à análise de conteúdo (BARDIN, 2011) por duas avaliadoras independentes que, diante de discordâncias, consultaram uma terceira avaliadora para decidir como as respostas das crianças seriam agrupadas em categorias temáticas. Como se trata de uma pesquisa predominantemente qualitativa, portanto, não totalmente assim caracterizada, foram calculadas frequências e porcentagens de respostas nas categorias empiricamente elaboradas (ou seja, a partir das próprias falas das crianças). Assim, há análise quantitativa no trabalho à medida que se buscou também conhecer os conteúdos mais citados pelas crianças, por gênero e por tipo de escola (pública ou privada), bem como a análise qualitativa de conteúdos independentemente da frequência obtida.

\section{RESULTADOS}

Os resultados são detalhados mediante seis tabelas e fornecimento de exemplos das unidades temáticas que criaram as categorias de respostas. São apresentados, nesta ordem, os seguintes resultados: conceito de lazer, atividade de lazer, companhia para o lazer, aprendizagem com o lazer, e atividades de lazer que faria mais e que deixaria de fazer.

A TAB. 1 mostra as categorias formadas com as respostas das crianças para o conceito de lazer, por sexo e por tipo de escola. Das 41 crianças entrevistadas, 31 forneceram conteúdos para análise. Não constam na TAB. 1 as respostas citadas por apenas uma criança cada, conforme segue: dormir e descansar para poupar energia, passar o tempo, tomar banho/almoçar/fazer dever de casa, coisas do dia a dia, mãe brincar com o filho depois do trabalho. Para 10 crianças que não souberam responder o 
que é lazer, a pesquisadora forneceu um conceito de lazer a fim de que as demais perguntas da entrevista pudessem ser respondidas.

TABELA 1

Frequência de respostas sobre o conceito de lazer, por gênero e tipo de escola $(n=31)$

\begin{tabular}{l|c|c|c|c|c}
\hline \multirow{2}{*}{ Definição de lazer } & \multicolumn{2}{|c|}{ Gênero } & \multicolumn{2}{c|}{ Tipo de escola } & $\mathrm{f}$ \\
\cline { 2 - 6 } & $\mathrm{F}$ & $\mathrm{M}$ & Pública & Privada & Total \\
\hline Atividades em geral & 6 & 3 & 3 & 6 & 9 \\
Diversão & 4 & 4 & 1 & 7 & 8 \\
Casa/ onde moramos & 2 & 3 & 4 & 1 & 5 \\
Lugar & 2 & 3 & 1 & 4 & 5 \\
Brincar/ brincadeiras & 3 & 2 & 2 & 3 & 5 \\
Tempo & 3 & 2 & 1 & 4 & 5 \\
Bem-estar & 3 & 1 & 1 & 3 & 4 \\
Descanso & 1 & 3 & - & 4 & 4 \\
Algo que gosta de fazer & 2 & 1 & - & 3 & 3 \\
\hline Fonte: dados da pesquisa. & \multicolumn{7}{|l}{}
\end{tabular}

Os temas contidos nas categorias para a definição de lazer foram os seguintes:

- atividades em geral: passear, sair com os pais, sair de casa, ir a clubes, cinema, shopping, andar de bicicleta, etc.

- diversão: se divertir, atividades para se divertir.

- casa/ onde moramos: é a nossa casa, onde a gente mora, etc.

- lugar: clube, lugar tranquilo, um lugar onde se sente confortável, etc.

- tempo: horário para brincar, tempo que tem para fazer as atividades que quer e gosta, é quando faz algo que gosta porque tem tempo livre.

- bem-estar: ficar tranquilo e comer muitas coisas, se sentir à vontade, se sentir bem, é quando você se sente bem, um lugar onde se sente confortável.

- algo que se gosta de fazer (inespecífico): é quando faz algo que gosta porque tem tempo livre, coisas que gosta de fazer, fazer alguma coisa legal.

A TAB. 2 mostra as respostas de 40 crianças sobre suas atividades de lazer (01 
criança não respondeu). As categorias com até 3 respostas constam na (TAB. 2). As respostas de frequência um ou dois foram as seguintes: ir a fazendas/sítios, passear, caminhar, cinema, ir à BHTrans com a escola, zoológico, olhar para o tempo, ouvir música, ficar em casa, acampamento da igreja, arrumar a cama, inventar histórias a partir de desenhos no DVD, tomar banho.

As seguintes categorias da TAB. 2 requerem exemplo sobre seus conteúdos:

- atividades físicas: jogar basquete, jogar peteca, correr, nadar, andar de bicicleta, de patins, de skate, jogar paintball.

- brincar (em geral): de um monte de coisa, com irmãos, na pracinha, com colegas.

- atividades com a mãe: ir à "cidade" (fazer o cabelo, pagar contas, compras), sair com a mãe (sorveteria, lugar que vende jogo de videogame), ajudar a mãe.

- brincadeiras: esconde-esconde, casinha, na casa de colegas e da avó, com cachorro.

- brincar ao ar livre: de papagaio/ pipa, de peteca, de vôlei, rolar na grama.

- aulas formais fora da escola: judô, futebol e balé.

- atividades de alimentação: sair com a mãe pra comer salgado, restaurante, almoçar/ jantar, comer, almoçar fora.

- atividades acadêmicas: fazer para casa, estudar, ler livros da escola.

- atividades com amigos: ir à casa de amigos (andar, conversar e brincar), convidar amigos para ir à sua casa, encontrar com amigos. 


\begin{tabular}{l|c|c|c|c|c}
\hline \multirow{2}{*}{ Atividade } & \multicolumn{2}{|c|}{ Gênero } & \multicolumn{2}{c|}{ Tipo de escola } & $\mathrm{f}$ \\
\cline { 2 - 6 } & $\mathrm{F}$ & $\mathrm{M}$ & Pública & Privada & Total \\
\hline Televisão & 7 & 6 & 5 & 8 & 13 \\
Descanso/ repouso & 3 & 8 & 3 & 8 & 11 \\
Atividades físicas & 5 & 5 & 1 & 9 & 10 \\
Brincar (em geral) & 4 & 6 & 4 & 6 & 10 \\
Mexer no computador & 1 & 7 & 3 & 5 & 8 \\
Conversar & 2 & 6 & 5 & 3 & 8 \\
Ir ao shopping & 7 & 1 & - & 8 & 8 \\
Jogar futebol & 2 & 5 & 3 & 4 & 7 \\
Ir a parques & 5 & 2 & 1 & 6 & 7 \\
Ir ao clube & 5 & 2 & - & 7 & 7 \\
Atividades com a mãe & 6 & 1 & 3 & 4 & 7 \\
Brincadeiras & 3 & 3 & 4 & 2 & 6 \\
Videogame (genérico) & 1 & 5 & 2 & 4 & 6 \\
Atividades de alimentação & 3 & 3 & 3 & 3 & 6 \\
Atividades acadêmicas & 3 & 3 & 1 & 5 & 6 \\
Atividades com amigos & 2 & 4 & 1 & 5 & 6 \\
Brincar com brinquedos & 4 & 1 & 4 & 1 & 5 \\
Brincar ao ar livre & - & 5 & 4 & 1 & 5 \\
Ir à casa de parentes & 4 & 1 & 2 & 3 & 5 \\
Brincar com jogos & 2 & 2 & 2 & 2 & 4 \\
Brincar de bola/ jogar bola & 1 & 3 & 1 & 3 & 4 \\
Jogos eletrônicos & - & 4 & 1 & 3 & 4 \\
Viajar & 2 & 2 & 1 & 3 & 4 \\
Aulas formais fora da escola & 1 & 3 & - & 4 & 4 \\
Ler/folhear livros, revistas & 1 & 2 & 2 & 1 & 3 \\
\hline Fonte: dados da pesquisaryyyyyyyyyyy & & & & &
\end{tabular}

Fonte: dados da pesquisa.

A TAB. 3 exibe as categorias de respostas sobre as pessoas que acompanham as crianças entrevistadas nas atividades de lazer que elas afirmam realizar. Das 41 crianças participantes, 27 forneceram respostas sobre a companhia para o lazer. Não constam na tabela as seguintes respostas: "sozinha" (02 meninas de escola pública), "a gente" (01 menina de escola privada), e "escola" (01 menina de escola pública).

TABELA 3

Frequência de respostas sobre a companhia no lazer, por gênero e tipo de escola $(n=27)$

\begin{tabular}{l|c|c|c|c|c}
\hline \multirow{2}{*}{ Companhia no lazer } & \multicolumn{2}{|c|}{ Gênero } & \multicolumn{2}{c|}{ Tipo de escola } & $\mathrm{f}$ \\
\cline { 2 - 6 } & $\mathrm{F}$ & $\mathrm{M}$ & Pública & Privada & Total \\
\hline Pais & 7 & 4 & 4 & 7 & 11 \\
Amigos & 2 & 6 & 3 & 5 & 8 \\
Irmãos & 3 & 4 & 1 & 6 & 7 \\
Colegas & - & 5 & 3 & 2 & 5 \\
Primos & 1 & 3 & 1 & 3 & 4 \\
Família & 1 & 3 & 2 & 2 & 4 \\
Outras companhias & 2 & 4 & 2 & 4 & 6 \\
\hline
\end{tabular}

Fonte: dados da pesquisa.

A TAB. 4 apresenta as categorias sobre o que o lazer ensina, com base nas 
respostas de 37 crianças. Três crianças entendem que o lazer nada ensina, e 01 não soube responder. Um menino e 01 menina de escola privada responderam "brincar", e 01 menina de escola privada respondeu "direito de brincar" - resultados que não constam na TAB. 4.

TABELA 4

Frequência de respostas sobre o que o lazer ensina, por gênero e tipo de escola $(n=37)$

\begin{tabular}{l|c|c|ccc|c}
\hline \multirow{2}{*}{ Ensinamento } & \multicolumn{2}{|c|}{ Gênero } & \multicolumn{2}{c|}{ Tipo de escola } & $\mathrm{f}$ \\
\cline { 2 - 6 } & $\mathrm{F}$ & $\mathrm{M}$ & Pública & Privada & Total \\
\hline Aprender coisas novas & 7 & 7 & 7 & 7 & 14 \\
Novidades no brincar & 4 & 6 & 2 & 8 & 10 \\
Diversão & 2 & 6 & 3 & 5 & 8 \\
Coisas para o futuro & 3 & 4 & 6 & 1 & 7 \\
Habilidades sociais & 4 & 3 & 3 & 4 & 7 \\
Distração/ descanso & 3 & 2 & 1 & 4 & 5 \\
Disciplina/ respeito & 4 & - & 3 & 1 & 4 \\
Habilidades no futebol & - & 4 & 2 & 2 & 4 \\
Ações altruístas & 3 & - & 3 & - & 3 \\
Sentimentos positivos & 1 & 2 & 2 & 1 & 3 \\
\hline
\end{tabular}

Fonte: dados da pesquisa.

As categorias sobre o conteúdo dos ensinamentos do lazer continham os seguintes conteúdos:

- aprender coisas novas, aprimorar habilidades: ter criatividade, aprender a pensar, a saber/aprender falar inglês (aprende com os jogos de videogame), se organizar, tocar violão, jogar vôlei, cozinhar, controlar a velocidade (na natação), fazer exercícios físicos/ficar bom para a saúde, para passar de ano/estudar mais, desenhar, cuidar das plantas, sobre o trânsito, sobre bichos, sobre a Bíblia, lugares novos, aprender em sites de pesquisa.

- novidades/alterações no brincar: novas brincadeiras/jogos/formas de brincar/jogar, aprender "manhas" do videogame, montar brinquedos quebrados.

- diversão: ensina a se divertir, como se divertir corretamente (sem machucar, com respeito), aprendo a me divertir mais.

- futuro: arrumar casa/ fazer comida para quando casar, quando for grande vai saber 
várias coisas (arrumar a casa, já vai ter feito faculdade, porque não vai ter a mãe a vida toda), não fazer coisas ruins quando crescer (não ser bandido, arruaceiro), ensina que tem que estudar muito para ser um jogador ou policial ou fazer faculdade (quando conversa com a família), posso ser uma desenhista no futuro, brincar para não ficar velho rápido.

- habilidades sociais: fazer mais amizades, conhecer pessoas novas, ficar em grupo, conversar com as pessoas, conviver, trabalhar em grupo, não ter vergonha.

- distração/descanso: se distrair, relaxar, ficar mais quieto.

- disciplina/respeito: respeitar, ter educação, respeitar os pais, brincar sem brigar.

- ações altruístas: dividir com os irmãos, compartilhar, ajudar as pessoas.

- sentimentos positivos/bem-estar: a ser feliz, a viver, alegria, aproveitar a vida.

A TAB. 5 diz respeito às atividades de lazer que as crianças gostariam de fazer mais. Não constam na TAB. 5 as seguintes respostas com frequência 01, conforme segue: aprender a trabalhar, não ficar de castigo, sair de casa, e assistir TV; também não constam as seguintes categorias, com apenas 02 respostas em cada: ficar/viajar mais com a família, sair da cidade, e instrumentos musicais.

TABELA 5

Frequência de respostas sobre atividades que as crianças gostariam de fazer mais, por gênero e tipo de escola

\begin{tabular}{l|c|c|c|c|c}
\hline \multirow{2}{*}{ Atividade } & \multicolumn{2}{|c|}{ Gênero } & \multicolumn{2}{c|}{ Tipo de escola } & $\mathrm{f}$ \\
\cline { 2 - 6 } & F & M & Pública & Privada & Total \\
\hline Futebol & - & 7 & 1 & 6 & 7 \\
Esportes & 5 & 2 & 1 & 6 & 7 \\
Jogar bola & 1 & 5 & 6 & - & 6 \\
Outras atividades físicas & 3 & 2 & 3 & 2 & 5 \\
Brincar & 4 & 1 & 4 & 1 & 5 \\
Mexer/jogar no computador & 1 & 4 & 1 & 4 & 5 \\
Frequentar mais espaços urbanos & 5 & - & 1 & 4 & 5 \\
Videogame & - & 4 & 3 & 1 & 4 \\
Atividades acadêmicas & 2 & 1 & 3 & - & 3 \\
\hline
\end{tabular}

Fonte: dados da pesquisa.

Os conteúdos das categorias da TAB. 5 foram os seguintes, com exceção das 
categorias cujo conteúdo as nomeia:

- esportes: basquete, handball, natação, vôlei, hipismo, nadar, peteca.

- outras atividades físicas: balé, correr demais com a bicicleta, pique-cola, escondeesconde, pular corda, paintball.

- brincar: brincar (em geral), montar aviões de isopor, montar carrinhos com controle remoto, brincar de Barbie, brincar na rua, brincar com primos, amigos.

- frequentar mais espaços urbanos: ir ao zoológico, ir a parques (em geral e de diversão), ir à igreja, ir ao clube.

- atividades acadêmicas: Português, estudar, brincar na Educação Física (fazer ginástica, aprender a jogar futebol, queimada, etc.).

A TAB. 6 apresenta as atividades que 19 das crianças entrevistadas deixariam de fazer como lazer, com a justificativa da criança, quando fornecida por ela. As seguintes atividades obtiveram uma única resposta: arrumar a casa, ir ao cinema (gasta muito dinheiro e não sobra para sua casa), tomar banho, desenhar com lápis (é difícil), ir ao Parque Ecológico (tem muita gente estranha). Duas meninas, uma de cada escola, deixariam de assistir televisão (para ajudar mais a mãe; se eu conseguisse, porque ver TV engorda).

TABELA 6

Frequência de respostas sobre atividades que as crianças deixariam de fazer, por gênero e tipo de escola

\begin{tabular}{|c|c|c|c|c|c|}
\hline \multirow{3}{*}{ Atividade } & \multicolumn{5}{|c|}{$(n=19)$} \\
\hline & \multicolumn{2}{|c|}{ Gênero } & \multicolumn{2}{|c|}{ Tipo de escola } & $\mathrm{f}$ \\
\hline & $\mathrm{F}$ & M & Pública & Privada & Total \\
\hline Brincar & 4 & 2 & 5 & 1 & 6 \\
\hline Atividades esportivas & 2 & 2 & 2 & 2 & 4 \\
\hline Atividades acadêmicas & 3 & 1 & 1 & 3 & 4 \\
\hline
\end{tabular}

Fonte: dados da pesquisa.

Os conteúdos das categorias foram os seguintes:

- brincar: peteca (porque não é muito boa), carrinho (está ficando velho e não gosta), escolinha com a mãe (mãe faz atividades difíceis), boneca (mãe dá bonecas e ela não 
usa), brincar fora de casa (gosta de brincar em casa no computador).

- atividades esportivas: jogar futebol (muitos meninos que ficam zoando, fica triste, ofende, porque é menina), vôlei, natação (é cansativo), tênis (pai pediu e é tenista).

- atividades acadêmicas: dever de casa (falta vontade/ânimo, é chato, não gosta), deixou de fazer Kumon (já fazia muitas atividades extras), mãe manda ajudar irmão a ler.

Como explicitado anteriormente, por se tratar de uma pesquisa de natureza descritiva e exploratória, com interesse qualitativo e quantitativo, dada a escassez de estudos desta natureza no Brasil. A seguir são discutidos os resultados à luz da literatura disponível sobre os temas pesquisados. Cabe mencionar que foram escolhidos os dados mais significativos, na visão das autoras, para serem discutidos, dada a amplitude de resultados. Assim, serão discutidos resultados tanto com frequência elevada, como resultados com baixa frequência de respostas mas com conteúdo relevante aos objetivos do trabalho.

\section{DISCUSSÃO}

Os principais resultados serão discutidos a seguir. Afora estes, as pesquisadoras não entendem que os demais resultados não sejam significativos, dado que o presente estudo não é quantitativo, mas de natureza híbrida (quali-quantitativo), como já explicitado. Todavia, buscou-se apresentar todos os dados encontrados na seção anterior, mesmo que a sua totalidade não seja discutida, para que sejam compartilhados os dados de pesquisa e para que a voz das crianças seja publicada na presente oportunidade.

Inicialmente é preciso comentar a respeito das 10 crianças (aproximadamente 
$25 \%$ da amostra) que não souberam responder o que é lazer. Poder-se-ia considerar que, pela idade das crianças ( 9 a 10 anos), seria esperado que conseguissem dar conta do conceito, mesmo que com aspectos mais concretos de suas experiências, como argumenta Piaget (1964/1999) ao classificar o modo de pensar das crianças desta faixa etária. Todavia, é lícito considerar que o vocabulário destas crianças ainda não abrigue termos abstratos como "lazer", desde que esta palavras é pouco usada em seu cotidiano. Portanto, a experiência de lazer está presente nestas crianças, e o fato de não saberem definir a palavra "lazer" não é indicativo da inteligência das mesmas nem de qualquer tipo de incapacidade cognitiva. Cultura e cognição estão interconectados desde sempre, e isso é especialmente relevante quando se discutem temas como o lazer.

As práticas de lazer das crianças trouxeram conteúdos temáticos ricos, os quais foram organizados em categorias temáticas detalhadas, como se pode notar na TAB. 2. A razão para tal é de que comumente a literatura empírica descreve as atividades infantis mediante categorias muito amplas de conteúdos, por exemplo, indicando apenas "brincar" e sob tal título incluindo uma variedade de formas lúdicas, com características distintas (diferentes em contexto, companhia, frequência, etc.). Objetivando aprofundar o tema por meio de análise qualitativa, optou-se pelo detalhamento mesmo em detrimento de frequência de respostas por categoria.

Sobre o conceito de lazer, as crianças demonstraram certa dificuldade, como comentado anteriormente, trazendo muitas respostas que não puderam ser agrupadas em categorias separadas, quais sejam, as "atividades em geral". Todavia a segunda categoria com maior número de respostas foi “diversão", o que é totalmente condizente com o esperado para uma definição de lazer, e mostrando que as crianças entrevistadas tem alguma noção de o que se está falando. Soma-se a ela as respostas de "algo que 
gosta de fazer". Na mesma direção de Piaget (1964/1999), as crianças, portanto, entendem o que experienciam, mas podem ter dificuldade, no momento, para descrever detalhadamente a experiência. Também é interessante notar que, ao contrário do que se projeta na literatura científica nacional publicada, os conteúdos sobre "brincar" não foram os mais citados pelas crianças, nessa questão.

As respostas sobre as atividades de lazer das crianças participantes mostram, como intencionado, a diversidade de conteúdos na fala destas crianças. Por se tratar de um estudo quali-quantitativo, optou-se por não criar categorias mais abrangentes, e explicitar melhor alguns indícios do pensamento infantil sobre suas experiências de lazer. As quatro primeiras categorias de respostas, com frequência mínima de 10, sugerem um quadro menos catastrófico sobre o uso do tempo livre das crianças. Ao menos é o que este estudo indica, visto que, mesmo havendo frequência grande de respostas (dado o tamanho da amostra) para atividades como assistir televisão (atividade mais citada), ainda assim há muitas respostas sobre descanso, atividades físicas e brincar. A este respeito, os trabalhos de Giacomoni, Souza e Hutz (2012a; 2012b) também indicam que a maioria das crianças inclui o lazer na definição de felicidade, descrito como brincar e realizar atividades físicas divertidas. Os resultados do presente estudo e daquele, portanto, convergem no que diz respeito a estes aspectos.

Mesmo sem a condução de testes estatísticos é possível visualizar na tabela algumas diferenças acentuadas de gênero nas atividades. Mexer no computador, jogar videogame e jogos eletrônicos foram citados maciçamente por meninos, bem como futebol e jogar bola. As meninas se destacaram em respostas como atividades com a mãe e atividades que envolvem deslocamento da moradia, como ir a shopping, clube, parque, casa de parentes. 
É possível que as meninas estejam, ao mesmo tempo, sendo privilegiadas por atividades mais diversificadas, que as levam para fora do domínio doméstico, mas ao mesmo tempo é possível que estejam, nessas atividades, cumprindo com um papel coadjuvante de acompanhantes dos pais, especialmente mães. Se for este o caso, perdese um pouco do que seja o lazer, dado que se assume que este precisa envolver certa liberdade, senão de escolha, ao menos do nível de envolvimento. Alguma negociação, por exemplo, poder-se-ia esperar que a família realizasse em prol do desenvolvimento da autonomia da criança, em especial na idade de 9 a 10 anos, como no caso da presente pesquisa. Se ir ao shopping não é escolha da criança, pelo menos uma vez lá ela possa fazer algo de eu agrado. E isso, logicamente, não deve incorrer automaticamente em lhe comprar presentes ou guloseimas.

Já com respeito aos meninos, não foi realizada uma análise que considerasse a exclusividade das categorias, ou seja, que um menino que joga futebol ou outro esporte bem como mexe no computador tenha, na verdade, melhor prognóstico, por assim dizer, do que aquele menino que cita como lazer apenas mexer no computador e jogar videogame. A obesidade infantil já é um problema de saúde pública, e atentar para este aspecto é cuidar da criança em termos de saúde integral. De todo modo, os estudos de Lourenço e Jinzenji (1999; 2000) já sinalizavam que, à medida que a televisão foi se tornando mais acessível e popular, as crianças mineiras, ao longo das décadas, passaram a citá-la mais e mais como algo significativo do cotidiano infantil.

Outra categoria que se destaca é a de atividades físicas, dado que a maioria das respostas vem de crianças de escola privada. Dois pontos podem ser considerados sobre essa disparidade: o primeiro seria argumentar que as escolas privadas possuem professores de educação física mais motivados (em termos de remuneração) para 
lecionar, bem como possuem mais equipamentos à disposição para promover as aulas; o segundo ponto seria argumentar que as crianças de escola privada vem de famílias financeiramente melhor supridas, que podem, e muito provavelmente o fazem, estimular os filhos a frequentarem atividades físicas em aulas particulares de natação, futebol, tênis, inglês, etc. Seja qual foi o argumento, que sugere diferença de nível socioeconômico, o que se percebe, ainda, é relação estreita entre renda familiar e lazer na infância, afora, claro, a situação precária das escolas públicas.

As respostas das crianças sobre as companhias no lazer mostram, mais uma vez, que os pais desempenham um papel importante nessa esfera da vida; afinal, são crianças, e requerem acompanhamento e orientação familiar também nos momentos de lazer. Em segundo lugar apareceram os amigos, e a este respeito cabe citar que as amizades tem forte significado na faixa etária estudada. As crianças dessa idade já entendem que amizade envolve diversão, companheirismo, troca, reciprocidade, respeito. A literatura científica destaca, ademais, que as relações de pares são promotoras de desenvolvimento e aprendizagem, e o lazer não fica de fora dessa equação. Mas o que se pretende destacar, aqui, é também que não somente com colegas e amigos que brincar e se divertir é possível, visto que as crianças indicaram, em terceiro lugar na frequência de respostas, os irmãos. São escassas as pesquisas brasileiras sobre relações fraternas na infância e seu papel sobre o desenvolvimento infantil, assim como não se encontram à disposição estudos sobre lazer em irmãos na infância.

Foi igualmente interessante a diferença de escola para a questão da aprendizagem envolvida no lazer. "O que o lazer ensina?", foi perguntado às crianças, e aquelas estudantes de escola privada indicaram muito "novidades", o que pode ser 
reflexo de maiores oportunidades de lazer através de atividades jogos eletrônicos, fazer natação, inglês, dentre outras que podem envolver maiores gastos familiares, como as respostas indicaram. Já as crianças de escola pública frisaram bastante a questão de que o lazer ensina para o futuro. Dessas respostas é possível associar aquelas práticas que atrelam o lazer e a prática de esportes à "prevenção" ao uso de drogas e à delinquência, dado o tipo de resposta como "não ser bandido ou arruaceiro". Infelizmente ainda há ações governamentais, e não governamentais (mas envolvendo verba pública), voltadas para crianças de comunidades carentes ou nas quais há elevado índice de violência. Esse uso do lazer para "domesticar" ou para evitar o que seria "natural" de acontecer é, no mínimo, um insulto não somente à autonomia das crianças, mas um desrespeito à sua pessoa em formação, cujo caráter não é dado a chance de conhecer, mas previsto e prescrito. De outro modo, outras interpretações são válidas para a categoria “coisas para o futuro" no que diz respeito ao que o lazer ensina. Com a elevada frequência de respostas com atividades com os pais, as crianças podem ter pensado que em sua companhia estão aprendendo a fazer atividades adultas, como dirigir, fazer compras, pagar contas, etc. Há respostas apontando nesse sentido, como aprender a cozinhar.

Sobre as atividades que as crianças gostariam de praticar mais, as quatro primeiras categorias indicam, de modo geral, que as crianças do presente estudo estão requisitando mais atividades físicas e esportivas. Isso parece muito apropriado, especialmente se se está lidando atualmente com uma verdadeira epidemia de obesidade infantil. As próprias crianças estão pedindo, em seu lazer, mais atividades de movimento, de esforço físico, de esporte. E com a vinda das olimpíadas e da copa do mundo de futebol para o Brasil nos próximos anos, espera-se que haverá empenho governamental em apoiar ações dessa natureza voltadas para crianças. 
Com relação às atividades que as crianças deixariam de fazer, pouco se pode discutir sobre elas, dada a pequena quantidade de crianças que responderam a esta questão. Todavia, parece que as crianças de escola privada, especialmente meninas, gostariam de ter menos atividades acadêmicas em seu tempo liberado da escola. Em outras palavras, querem levar menos escola para casa. Um possível investimento maior em meninas nas atividades acadêmicas extracurriculares pode ser uma resposta da presente geração de mães e educadoras a proporcionar a melhor educação formal disponível para a futura mulher, especialmente pela atualidade do trabalho feminino não doméstico, concomitante às tarefas do lar e da criação dos filhos.

\section{CONSIDERAÇÕES FINAIS}

O presente trabalho buscou conhecer o conceito de lazer de crianças, suas práticas de lazer, a companhia nessas práticas, se se aprende algo com o lazer, quais atividades faria mais e quais deixaria de fazer. Em resumo, o lazer para estas crianças é realizar atividades generalizadas com os pais e se divertir. Olhar televisão, descansar, fazer atividades físicas e brincar são as atividades que as crianças realizam em suas vidas como lazer, principalmente na companhia dos pais, amigos e irmãos. $\mathrm{Na}$ visão dessas crianças, o lazer ensina novidades de toda natureza. Gostariam de realizar mais atividades físicas e esportivas, e pouco se manifestaram quanto a atividades de lazer que deixariam de realizar.

A principal limitação do presente estudo, a priori, é o tamanho da amostra. De um lado, dado o desenho quali-quantitativo escolhido para o mesmo, não estava exatamente prevista uma amostra sobre a qual predominassem testes de significância estatística. Por outro lado, não são possíveis conclusões que pudessem fornecer maiores 
indicativos para o trabalho prático com crianças no campo do lazer. Ainda assim, são sinalizadas algumas questões pontuais, tanto de origem quantitativa como qualitativa, para que sejam mais investigadas em esforços científicos futuros.

Com respeito a pesquisas futuras, seria interessante investigar mais como ocorre o lazer em família, como os pais concebem o lazer, como entendem o papel da criança enquanto participantes, protagonistas ou apenas acompanhantes de atividades que, como se sabe, são promotoras de diversão, descanso e desenvolvimento. Também parece haver um silêncio sobre as experiências de lazer compartilhadas por irmãos.

Como argumentado no início do presente texto, ainda há muito a se estudar com relação ao lazer em crianças. Trata-se de uma dimensão importante do bem-estar subjetivo e da satisfação de vida infantil, como já vem sendo discutido por Giacomoni, Souza e Hutz (2012a; 2012b). A psicologia positiva precisa atentar mais para o campo de estudos do lazer, e este último pode se enriquecer com a perspectiva subjetiva do estudo do bem-estar e da felicidade, especialmente com o foco no descanso, no prazer e no desenvolvimento humano.

\section{REFERÊNCIAS}

BARDIN, L. Análise de conteúdo. ed. rev. amp. São Paulo: Edições 70, 2011. 279p.

DIAS, A. O. Idoso, lazer, grupos de convivência: uma comparação entre participantes, não participantes e egressos. 2012. 153 f. Dissertação (Mestrado) - Escola de Educação Física, Fisioterapia e Terapia Ocupacional, Universidade Federal de Minas Gerais, Belo Horizonte, 2012.

DUMAZEDIER, J. Sociologia empírica do lazer. São Paulo: Perspectiva, 1979. 249 p.

GIACOMONI, C. H.; SOUZA, L. K. de; HUTZ, C. S. O conceito de felicidade em crianças. Manuscrito submetido, 2012a. 25p. 
GIACOMONI, C. H.; SOUZA, L. K. de; HUTZ, C. S. A visão das crianças sobre a felicidade. Manuscrito submetido, 2012b. 20p.

HUEBNER, E. S.; GILMAN, R. An introduction to the multidimensional student's life satisfaction scale. Social Indicators Research, v. 60, p. 115-122, 2002.

LOURENÇO, E.; JINZENJI, M.Y. Ideais das crianças mineiras no século XX: mudanças e continuidades. Psicologia: Teoria e Pesquisa, v. 16, n. 1, p. 41-48, 2000.

LOURENÇO, E.; JINZENJI, M.Y. Os ideais e interesses das crianças mineiras revisitados. In: XVIII Encontro Anual Helena Antipoff, 1999, Belo Horizonte. Boletim do Centro de Documentação e Pesquisa Helena Antipoff. Belo Horizonte: CDPHA, 1999. v. 14. p. 53-69.

MARCELlinO, N. C. Estudos do lazer: uma introdução. Campinas: Autores Associados, 1996. 100 p.

MOURA, G. A. de. Experiências de lazer de idosos independentes institucionalizados. 2012. 188 f. Dissertação (Mestrado) - Escola de Educação Física, Fisioterapia e Terapia Ocupacional, Universidade Federal de Minas Gerais, Belo Horizonte, 2012.

PIAGET, J. Seis estudos de psicologia. 25. ed. Rio de Janeiro: Forense Universitária, 2011. 156 p.

ROCHA, M. A.; SOUZA, L. K. de. A criança e o tempo liberado da escola. Manuscrito submetido, 2012a. 19 p.

ROCHA, M. A.; SOUZA, L. K. de. As crianças e o lazer em família. Manuscrito submetido, 2012b. 18 p.

ROCHA, M. A.; SOUZA, L. K. de. Um diálogo entre a psicologia positiva e os estudos do lazer. In: ISAYAMA, H. F.; SILVA, S. R. da (Org.). Estudos do lazer: um panorama. Rio de Janeiro: Apicuri, 2011. p. 97-110.

SELIGMAN, M. Felicidade autêntica: usando a psicologia positiva para a realização permanente. Rio de Janeiro: Objetiva, 2004. 333p. 


\section{ENDEREÇO DAS AUTORAS:}

Universidade Federal de Minas Gerais

Faculdade de Filosofia e Ciências Humanas - FAFICH

Departamento de Psicologia

Av. Antônio Carlos, 6627, sala F-4050,

Campus Pampulha

CEP: 31.270-901 - Belo Horizonte - Minas Gerais 